\title{
Effects of congenital hydrocephalus on the hypothalamic gonadotrophin-releasing hormone system
}

\author{
James P. Mcallister II, Ph.D., ${ }^{1-3}$ Ramin M. Abdolvahabi, M.D., Ph.D., ${ }^{1}$ Marion L. \\ Walker, M.D., ${ }^{4}$ Jerald A. Mitchell, Ph.D., ${ }^{2}$ and Hazel C. Jones, Ph.D. ${ }^{5}$ \\ Departments of ${ }^{I}$ Neurological Surgery, ${ }^{2}$ Anatomy and Cell Biology, and ${ }^{3}$ Pediatric Neurosurgery, \\ Children's Hospital of Michigan, Wayne State University School of Medicine, Detroit, Michigan; \\ ${ }^{4}$ Primary Children's Hospital, University of Utah School of Medicine, Salt Lake City, Utah; and \\ ${ }^{5}$ Department of Pharmacology, University of Florida School of Medicine, Gainesville, Florida
}

\begin{abstract}
Object. Despite the investigations that have linked hydrocephalus to reproductive system abnormalities, no researchers have attempted to identify the pathophysiological mechanism of this relationship. Because the role of the hypothalamic gonadotrophin-releasing hormone $(\mathrm{GnRH})$ system in the regulation of reproductive functions is well established, the authors used immunohistochemical and radioimmunoassay (RIA) techniques to determine the morphological and biochemical effects of hydro-
\end{abstract} cephalus on the hypothalamic GnRH system.

Methods. Hypothalamic GnRH levels, fiber density, and cell types were studied in 21- and 50-dayold control and congenitally hydrocephalic Texas rats. Results of RIA indicated a significant $(8.4 \%)$ increase in GnRH in 21-day-old hydrocephalic rats $(9.17 \pm 0.64 \mathrm{pg} / \mathrm{ng}$ total protein) compared with that in controls $(0.97 \pm 0.74 \mathrm{pg} / \mathrm{ng}$ total protein). In addition, the 50-day-old hydrocephalic animals had a significantly higher level of GnRH compared with age-matched controls (20.4 pg/ng compared with $1.88 \pm 2.1 \mathrm{pg} / \mathrm{ng}$ total protein). This increase was accompanied by changes in the fiber appearance and a shift from low GnRH producing cells to high GnRH producing cells in the hydrocephalic animals; however, there was no significant difference in the fiber density between the control and hydrocephalic animals at 21 days. In addition, poor neurological scores correlated with the severity of hydrocephalus.

Conclusions. These results demonstrated that hypothalamic GnRH levels are significantly affected by fetal-onset hydrocephalus and that the mechanisms responsible for these effects may take place at the cellular rather than the gross structural level. Furthermore, they suggest that impairments in the GnRH system may be protracted in neonates and infants with hydrocephalus, and thus may be overcome by relatively early treatment with ventricular diversion. However, the clinical implications of GnRH perturbations in shunt-dependent patients must await a forthcoming study in shunted animals.

\section{KEY WORDS - hydrocephalus - precocious puberty - amenorrhea • gonadotrophin-releasing hormone $\bullet$ hypothalamus $\bullet$ third ventricle}

A UTHORS of several case reports and investigations have linked hydrocephalus to reproductive system abnormalities, namely, amenorrhea and precocious puberty. Hydrocephalus-related amenorrhea and precocious puberty have been reported in the literature. . $, 6-8,11,15,22,27,29,36,40,44,45,49$ A number of authors have suggested a relationship between precocious puberty and hydrocephalus. ${ }^{911,14,18,30,35,41,45-48}$ Moreover, the GnRH sys-

Abbreviations used in this paper: $\mathrm{GnRH}=$ gonadotrophin-releasing hormone; GnRH-IR = GnRH-immunoreactive; HTX = hydrocephalic Texas; $\mathrm{LH}=$ luteinizing hormone; $\mathrm{ME}=$ median eminence; OVLT = organum vasculosum of the lamina terminalis; $\mathrm{PBS}=$ phosphate-buffered saline; $\mathrm{PVH}=$ paraventricular hypothalamus; RIA = radioimmunoassay; $\mathrm{SD}=$ standard deviation. tem seems to be the mediator that links hydrocephalus to these reproductive abnormalities.

Despite these clinical data, no researchers have attempted to identify the pathophysiological mechanisms by which the GnRH system is affected. One possibility is that hydrocephalus impairs hypothalamic GnRH regulation by directly altering GnRH-containing neurons or the axonal tracts through which the peptide is transported. The periand paraventricular locations of the fiber tracts and the ME subject these structures to increased intracranial pressure and distention of the third ventricle. Most of the neurons that produce $\mathrm{GnRH}$ are situated anterior to the third ventricle, and thus may be relatively protected from the pressure and distortion caused by ventriculomegaly. Nev- 
ertheless, these cells could be affected retrogradely by direct influences on their axons.

The present study was undertaken to determine the morphological and biochemical effects of hydrocephalus on the hypothalamic GnRH system. Only one previous attempt has been made to evaluate the changes that occur in the hypothalamus during hydrocephalus, ${ }^{5}$ and this study was focused on vasopressin and prolactin alterations in the adult hamster. As described previously, ${ }^{23}$ the HTX rat model of inherited, fetal-onset aqueductal stenosis represents a particularly good experimental paradigm in which to study the effects of hydrocephalus on the developing brain. Obstructive hydrocephalus develops in the HTX rats subsequent to aqueductal stenosis between gestational Day 18 (in a 22-day gestation period) and postnatal Day $5 .{ }^{23,50}$ Ventriculomegaly develops progressively to reach severe proportions by Days 21 to 24 , and untreated animals usually die by 4 to 6 weeks of age. In view of the probable association between infantile hydrocephalus and the GnRH system, we hypothesized that GnRH axons and neurons would be structurally modified and that GnRH protein would be increased in the hypothalamus of developing HTX rats. This information forms the groundwork for further studies on the pathogenesis of hydrocephalusrelated reproductive disorders and on the effects of cerebrospinal fluid shunting.

\section{MATERIALS AND METHODS}

\section{Animal Population}

Experimental animals were selected based on the external appearance of the skull. Animals with an enlarged dome-shaped head were designated as hydrocephalic. All animals were weighed, and a simple neurological examination was performed before killing the rats. The following groups of animals were used: 1) 21-day-old hydrocephalic rats; 2) 21-day-old healthy littermate controls; 3) 50-day-old hydrocephalic rats; and 4) 50-day-old healthy littermate controls. Given that the onset of puberty occurs around Day 35, a killing Day 50 was chosen to evaluate $\mathrm{GnRH}$ changes during this important functional transition.

The HTX rat model of congenital hydrocephalus was used in this study, and all procedures were approved by the Wayne State University and University of Florida animal investigation committees in accordance with the National Institutes of Health Guide for the Care and Use of Laboratory Animals. Adult female rats with 3- to 6-day- old pups were shipped by same-day air cargo from the University of Florida at Gainesville. The animals were kept in an isolation room under conditions identical to those in our laboratory. Animals were housed one dam per $45 \times 24 \times 20-\mathrm{cm}$ clean plastic container and kept in a controlled environment with respect to temperature $\left(20-25^{\circ} \mathrm{C}\right)$ and photoperiod (12-hour light/dark cycle, lights on at 8:00 a.m.). They were given free access to food (Purina Laboratory Rat Chow) and water.

The severity of hydrocephalus was determined subjectively based on observations of cortical mantle thickness and lateral ventricle size in both fixed and fresh gross brains on their removal. Severity was classified as mild, moderate, and severe relative to each age group. This method has been used repeatedly in both clinical and experimental studies of hydrocephalus, ${ }^{12,23}$ and exact measurements of the temporal changes that occur in HTX rats with progressive ventriculomegaly have been reported ${ }^{24}$ and correlated with in vivo magnetic resonance imaging assessments of cortical mantle thickness. ${ }^{19}$

\section{Neurological Examination}

We devised a simple three-component examination to assess the neurological status of the pups. We quantified each component with a numeric score from 0 to 3 (Table 1 ), and the sum of these values was recorded as the neurological examination score. Alertness was assessed by observing the pattern of movement, feeding, and grooming. Balance was assessed by placing the animal on a round pipe (1/2-in diameter) and observing the animal's movements for 30 seconds. Strength was assessed by placing the animal on the examiner's gloved index finger, inverting the animal, and observing its ability to hold on to the finger without falling.

\section{Immunohistochemical Analysis}

The animals were deeply anesthetized with $4 \%$ chloral hydrate (3-5 ml, intraperitoneally) and perfused transcardially ( $4 \%$ paraformaldehyde $+5 \%$ acrolein) as previously described by Hoffman et al. ${ }^{20}$ The fixed brains were removed and placed in a 25\% sucrose solution for 2 days before sectioning. The brains were then cut frozen in the coronal plane at a thickness of $30 \mu \mathrm{m}$, and serial sections were stored in cryoprotectant solution $(500 \mathrm{ml}$ sodium phosphate buffer, $300 \mathrm{~g}$ sucrose, $10 \mathrm{~g}$ polyvinylpyrrolidone, and $300 \mathrm{ml}$ ethylene glycol; final volume $1000 \mathrm{ml}$; $0.1 \mathrm{M}, \mathrm{pH}$ 7.2).

Sections as far rostral as the OVLT $(0.5 \mathrm{~mm}$ anterior to

TABLE 1

Neurological examination scoring system

\begin{tabular}{llcc}
\hline \hline \multicolumn{1}{c}{ Alertness } & Balance & Strength & Rank \\
\hline $\begin{array}{l}\text { spontaneous movement, feeding, grooming } \\
\text { slow movements, spontaneous feeding, } \\
\text { poor grooming }\end{array}$ & $\begin{array}{l}\text { easily traverses pipe or keeps balance } \\
\text { for 30 sec } \\
\text { no traversing but keeps balance for }>15 \mathrm{sec}\end{array}$ & $\begin{array}{c}\text { able to climb or hold on } \\
\text { for 30 sec } \\
\text { holds on for 15-30 sec }\end{array}$ & 3 \\
$\begin{array}{c}\text { erratic movements, sparse feeding, } \\
\text { no grooming } \\
\text { no movement (even to stimuli), } \\
\text { no feeding, no grooming }\end{array}$ & keeps balance for 5-15 sec & holds on for 5-15 sec & 1 \\
\hline
\end{tabular}


the bregma) through the caudal extent of the mammillary bodies were selected at $120-\mu \mathrm{m}$ intervals and processed for GnRH immunohistochemistry according to the methods of Hoffman et al. ${ }^{20}$ The primary antiserum LR-1 (provided by Dr. Robert Benoit) recognizes both precursor and decapeptide forms of GnRH. Briefly, the brain tissue sections were removed from the cryoprotectant, rinsed in PBS, treated with $1 \% \mathrm{NaBH}_{4}$ solution (Sigma), rinsed, and incubated with the anti-GnRH antibody at a concentration of $1: 100,000$ in PBS with $0.4 \%$ Triton X-100 for 48 hours at $4^{\circ} \mathrm{C}$. After rinsing, the tissues were incubated in biotinylated goat anti-rabbit immunoglobulin G (heavy and light chains, Vector Laboratories) at a concentration of 1:600 in PBS with $0.4 \%$ Triton X-100 for 1 hour at room temperature, rinsed, and incubated for 1 hour in avidin-biotin complex solution $(4.5 \mu \mathrm{l}$ each/ml incubation mixture, Elite $\mathrm{ABC}$ kit, Vector Laboratories). After rinsing first in PBS and then in $0.175 \mathrm{M}$ sodium acetate, the staining of $\mathrm{GnRH}$ was accomplished by using a mixture of $\mathrm{H}_{2} \mathrm{O}_{2}(0.83 \mu \mathrm{l}$ of a $3 \%$ solution $/ \mathrm{ml}$ reaction solution $)$ and $3,3^{\prime}$-diaminobenzidine $(0.2 \mathrm{mg} / \mathrm{ml})$ in $0.175 \mathrm{M}$ sodium acetate. After staining for 2 to 8 minutes, the tissue was transferred to sodium acetate solution to stop the reaction, rinsed in PBS, and mounted on gelatin/chrome alumsubbed slides. After drying overnight, the slides were dehydrated in Histoclear (Sigma), and a cover slip of Histomount solution (VWR Scientific) was used. Sections were not counterstained.

\section{Light Microscopy Analysis}

For quantitative analysis of GnRH immunoreactivity, microdensitometry was performed on the portion of the GnRH system that contains nearly all of the fibers that course caudally from the cell bodies located more rostrally. This section includes the majority of GnRH-containing fibers (G Hoffman, personal communication) and corresponds to a coronal plane $3.30 \mathrm{~mm}$ posterior to the bregma according to the Paxinos and Watson atlas. ${ }^{39}$ With the aid of both the SPOT digital imaging camera system and the MetaMorph computer-assisted morphometric analysis program (Vision Core, Department of Anatomy and Cell Biology), three areas were quantified within the tissue section: 1) a region of the ME directly in the midline; 2) two areas symmetrically located just lateral to the ventral portion of the third ventricle excluding the ependymal lining, designated as the PVH; and 3) two areas of ependymal lining located approximately one third of the way toward the dorsal limit of the third ventricle. Threshold settings were adjusted manually to produce a digital image that most closely represented the section as visualized via light microscopy, and after initial tests to determine which illumination method was more accurate, bright-field optics were chosen. Counts of pixel density per unit area were obtained from each of the three sampled areas that included GnRH stained fibers. Similar counts were obtained from areas within the same section that did not include the GnRH labeling; such numbers represented artifactual background labeling and were subtracted from the respective initial counts to provide a single density measurement for each sample.

Moreover, a descriptive analysis using light microscopy of GnRH-containing neurons and fibers was conducted based on the following criteria: 1) density of axon fibers; 2 ) orientation and caliber of axon fibers; 3 ) size and number of axonal varicosities; and 4) proportion of spiny to smooth neuron cell bodies. Each of the first three parameters was ranked on a five-point scale, with 5 established as the maximal amount observed after an initial survey of all sections from all animals. Thus, a 5 ranking does not represent the only control value, because variations can exist within control animals and within different age groups. The higher rankings do, however, correspond to the most normal fiber orientation and pattern of varicosities. For the fourth parameter, the classification of spiny and smooth GnRH cell bodies was based on the descriptions of Wray and Hoffman. ${ }^{52}$ The person conducting these analyses was blinded to the experimental status of each animal. The objective observations of the fiber density were conducted on the areas previously chosen for computer-assisted densitometry.

The proportion of smooth to spiny GnRH cell bodies was evaluated in the preoptic area-anterior hypothalamic area, where GnRH perikarya are highly concentrated. Specifically, three consecutive sections, separated by intervals of $120 \mu \mathrm{m}$, were analyzed as follows: The first chosen section corresponded to where the OVLT formed the anterior wall of the third ventricle. The next rostral section sometimes included portions of the OVLT, and the rostral-most section was usually situated ventral to the septal region just anterior to the midline crossing of the anterior commissure. These three sections generally corresponded to levels $-0.26,0.20$, and $0.48 \mathrm{~mm}$ to the bregma, according to the atlas of Paxinos and Watson. ${ }^{39}$

\section{Gonadotrophin-Releasing Hormone RIA}

For GnRH protein quantification, the animals were decapitated after being anesthetized with $4 \%$ chloral hydrate (3- to 5-ml intraperitoneal injection). The rat brains were removed completely, and based on the atlas of Paxinos and Watson, ${ }^{39}$ the hypothalamus was rapidly isolated according to the following cuts: 1) a coronal section through the basal forebrain anterior to the optic chiasm approximately $0.5 \mathrm{~mm}$ anterior to the bregma; 2) a coronal section just posterior to the mammillary bodies approximately $5.0 \mathrm{~mm}$ posterior to the bregma; 3) a horizontal section just dorsal to the anterior commissure approximately $6.5 \mathrm{~mm}$ ventral to the bregma; and 4) two symmetrical sagittal sections approximately $2.5 \mathrm{~mm}$ lateral to the midline. Dissection of the hypothalamus in this fashion enabled us to include the majority of the GnRH-containing cell bodies and fibers based on the anatomical description by Hoffman. ${ }^{20}$ The hypothalami were rapidly frozen in liquid nitrogen and stored at $-80^{\circ} \mathrm{C}$.

The hypothalamic GnRH protein was extracted by methods described by Gautron et al. ${ }^{16}$ and lyophilized. Briefly, the tissue was homogenized (10\% weight/volume) in 2.0 $\mathrm{M}$ acetic acid by an ultrasonic homogenizer at $4^{\circ} \mathrm{C}$. The homogenate was processed in a centrifuge at $30,000 \mathrm{G}$ for 90 minutes and the supernatant was collected. The pellet was resuspended in $2.0 \mathrm{M}$ HOAc (half the volume of the initial homogenate) and centrifuged at $30,000 \mathrm{G}$ for 30 minutes, and the supernatant was combined with the supernatant from the first centrifugation, freeze-dried, and lyophilized. The lyophilized material was resuspended 


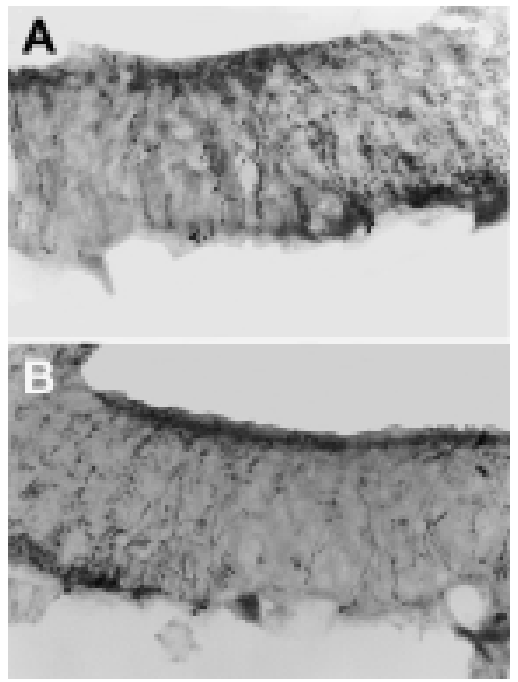

FIG. 1. Photomicrographs demonstrating coronal sections of the ME obtained in representative 21-day-old control rats (A) and a 21-day-old hydrocephalic HTX rat (B) and stained with antiGnRH antibody. Note the radial orientation of the GnRH-IR fibers with varicosities near the ventral surface of the ME as well as the similar labeling density between controls and hydrocephalic animals. Original magnification $\times 500$.

(half the volume of the initial homogenate at $4^{\circ} \mathrm{C}$ in $2 \mathrm{M}$ HOAc/methanol (30/70 vol/vol) and centrifuged at 10,000 $\mathrm{G}$ for 90 minutes. The pellet and the first and second supernatants were combined. A rotary vacuum evaporator at a maximum temperature of $30^{\circ} \mathrm{C}$ was used to evaporate the methanol. The pellet was resuspended in buffer $(\mathrm{pH}$ 7.2) containing $10 \mathrm{mM}$ Tris, $50 \mathrm{mM} \mathrm{KCl}, 5 \mathrm{mM}$ ethylenediaminetetraacetic acid, $7 \mu \mathrm{g} / \mathrm{ml}$ pepstatin, $10 \mu \mathrm{g} / \mathrm{ml}$ leupeptin, $1 \mu \mathrm{g} / \mathrm{ml}$ aprotinin, and $1 \mathrm{mM}$ dithiothreitol. The samples were stored at $-20^{\circ} \mathrm{C}$.

For RIA analysis, $500 \mu \mathrm{l}$ of each sample was processed and analyzed according to the method described by Nett et al. ${ }^{38}$ In addition, the total amount of protein in each sample was determined using the Lowry Protein Assay (Sigma Diagnostic). To partially correct for inconsistencies in extraction, the amount of GnRH per nanogram of total protein was calculated.

\section{Statistical Analysis}

All statistical analyses were performed using SPSS software (SPSS, Inc.). All data are presented as the means \pm $\mathrm{SD}$, and a statistical difference between the control and each of the animal groups was tested as the null hypothesis. The Levene Median test was used to determine the homogeneity of the variances, and a chi-square test was used to determine frequency distributions. A one-way analysis of variance on ranks (nonparametric), as well as the Games-Howell and Sidak tests, was used to test for differences between group means. The latter test was favored because it was more stringent and minimized the effect of false-positive data. Cross tabulations were used to describe relationships between two independent variables. The common correlation coefficient (Pearson product moment correlation coefficient), illustrated by scatter plots, was used to determine the strength of the correlations.
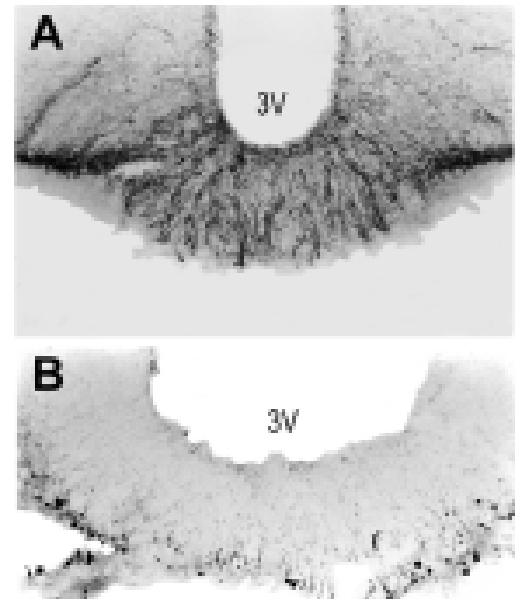

FIG. 2. Photomicrographs showing coronal sections of the hypothalamus at the level of the ME of representative 50-day-old control (A) and hydrocephalic (B) HTX rats stained with anti-GnRH antibody. Note the dramatic decrease in the intensity of GnRH fiber staining and the large varicosities near the ventral surface of the ME. Original magnification $\times 500.3 \mathrm{~V}=$ third ventricle.

\section{Gross Appearance}

\section{RESULTS}

Once dead, all control animals exhibited normal cerebral ventricles, whereas the hydrocephalic animals exhibited ventriculomegaly similar to that described previously. ${ }^{19,23,24}$ In all hydrocephalic animals, the occipital horns of the lateral ventricles were the most enlarged, and the overlying occipital cortex was thinned to less than $1 \mathrm{~mm}$. The frontal horns and cortex were less affected. Mild enlargement of the third ventricle was seen. During gross dissection of fresh rat brains, the tissue from the hydrocephalic animals was consistently edematous.

\section{Gonadotrophin-Releasing Hormone Fiber Appearance: 21 Days of Age}

Control animals exhibited abundant GnRH-IR fibers throughout the ME, PVH, and ependymal lining of the third ventricle (Fig. 1A). In the ME, these fibers coursed either radially to terminate on the ventral surface of the ME as large varicosities or longitudinally within the sagittal plane of the ME as small round profiles. These fibers and their varicosities were often found in proximity to large blood vessels. In the PVH, in addition to GnRH-IR fibers coursing longitudinally, others arched conspicuously between the ependymal lining and more ventrolateral portions of the hypothalamus. The ependymal lining of the PVH was densely packed with GnRH-IR fibers, most of which were oriented perpendicular to the ventricular wall. The ependymal lining dorsal to the PVH contained many GnRH-IR fibers; most of these were perpendicular to the ventricular wall, but some long fibers were directed dorsoventrally just lateral to the ependymal lining.

In general, hydrocephalic animals exhibited only slight reductions in GnRH immunoreactivity (Fig. 1B). This decrease was only apparent as diminished staining intensity in individual profiles; density, orientation, and varicosity size were unchanged. In some animals, the third ventricle was enlarged, and the ME thinned. 


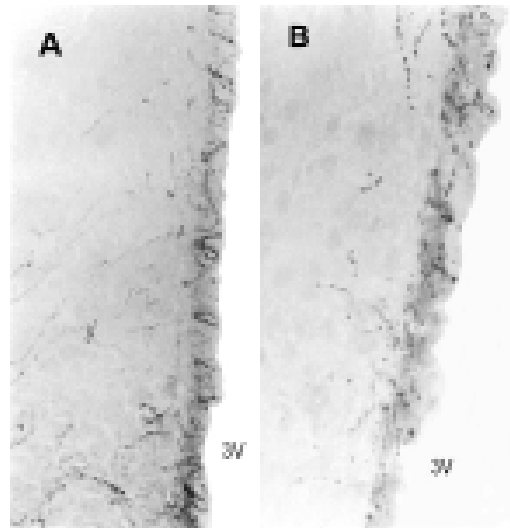

FIG. 3. High-magnification photomicrographs revealing the dorsal ependymal region from the same representative 50-day-old control (A) and hydrocephalic (B) brain tissue sections featured in Fig. 3. Note the slight reduction in GnRH fiber staining and the loss of fibers that arch ventrolaterally from the ependyma. Original magnification $\times 500$.

\section{Gonadotrophin-Releasing Hormone Fiber Appearance:}

50 Days of Age

Some of the 50-day-old control animals exhibited GnRH immunoreactivity in the ME, which appeared to be denser than that in controls at 21 days of age (Fig. 2A). In other 50-day-old controls, GnRH immunoreactivity in the ME was similar to that observed at 21 days. The pattern of GnRH staining in the PVH and the ependyma was nearly identical to that seen at 21 days. The most dramatic difference occurred in the 50-day-old hydrocephalic animal that was available for analysis (Fig. 2B). In this case, GnRH-IR fibers were less numerous and more faintly stained in the ME, although the orientation of the fibers was not changed. Very few fibers were found in the PVH, although some varicosities remained in the ependyma of this region. The ependyma located more dorsal to the floor of the third ventricle exhibited relatively normal GnRH immunoreactivity except for a reduction in the fibers that arched ventrolaterally (Fig. 3).

\section{Quantitative GnRH Fiber Immunoreactivity}

At 21 days of age, results of both digital densitometry and quantitative rankings revealed only slight decrements in GnRH density that were not statistically significant (Table 2). At 50 days of age, tissue sections from the hydrocephalic animal exhibited reductions in both quantitative measures of GnRH immunoreactivity in the ME and PVH. However, the ependyma lining the third ventricle in this animal did not demonstrate a similar decrease.

\section{Gonadotrophin-Releasing Hormone Cell Types}

Analysis of the region anterior to the third ventricle containing most of the GnRH cell bodies, the OVLT (Fig. 4), revealed two important features. First, the two populations of GnRH neurons previously described by Wray and Hoffman $^{51,52}$ as smooth and spiny based on cell body appearance were readily visible in the HTX rat (Fig. 5). Second, the relative percentages of these two cell types changed significantly $(\mathrm{p}<0.001)$ in both 21 - and 50-dayold hydrocephalic animals compared with age-matched controls (Fig. 6). As a reflection of normal development, the proportion of spiny neurons decreased from means of 41 and $30 \%$ in the 21- and 50-day controls, respectively. At 21 days, the hydrocephalic animals had significantly more $(47 \%)$ spiny cells, and this increase continued in the 50-day-old animal (75\%). Furthermore, these shifts in cell type were correlated with the severity of hydrocephalus in both age groups.

\section{Gonadotrophin-Releasing Hormone RIA}

A statistically significant $(p<0.05) 8.4 \%$ increase in $\mathrm{GnRH}$ occurred in 21-day-old hydrocephalic animals $(9.17 \pm 0.64 \mathrm{pg} / \mathrm{ng}$ total protein) compared with controls $(0.97 \pm 0.74 \mathrm{pg} / \mathrm{ng}$ total protein; Fig. 7$)$. In addition, the 50-day-old hydrocephalic animal exhibited a GnRH level that was $9.1 \%$ higher than that in age-matched controls $(20.4 \mathrm{pg} / \mathrm{ng}$ total protein compared with $1.88 \pm 2.1 \mathrm{pg} / \mathrm{ng}$ total protein).

\section{Body Weight and Neurological Evaluation}

All animals demonstrated normal weight gains, and once dead no differences were noted in the body weights of hydrocephalic animals compared with controls (Table 3 ). The results of neurological evaluation revealed a close correlation between the neurological examination and the severity of hydrocephalus (Table 4). All nonhydrocephalic animals at 21 and 50 days of age (including 87 shunt-

TABLE 2

Quantitative measures of GnRH immunoreactivity in control and hydrocephalic HTX rats at 21 and 50 days of age*

\begin{tabular}{|c|c|c|c|c|}
\hline \multirow[b]{2}{*}{ Animal Group } & \multirow[b]{2}{*}{$\begin{array}{l}\text { GnRH Densitometry } \dagger \\
\text { (pixels/unit area) }\end{array}$} & \multicolumn{3}{|c|}{ GnRH Density Rating } \\
\hline & & ME & $\mathrm{PVH}$ & Ependymal Lining \\
\hline $\begin{array}{l}\text { 21-day-old } \\
\text { control } \\
\text { hydrocephalic }\end{array}$ & $\begin{array}{l}63.2 \pm 27.9(5) \\
47.8 \pm 11.7(6)\end{array}$ & $\begin{array}{r}4.83 \pm 0.4(6) \\
3.7 \pm 1.5(6)\end{array}$ & $\begin{array}{l}4.0 \pm 1.3(5) \\
3.3 \pm 1.2(6)\end{array}$ & $\begin{array}{l}4.0 \pm 0.9(5) \\
3.5 \pm 1.6(6)\end{array}$ \\
\hline $\begin{array}{l}\text { 50-day-old } \\
\text { control } \\
\text { hydrocephalic }\end{array}$ & $\begin{array}{c}44.6 \pm 55.5(5) \\
1.67(1)\end{array}$ & $\begin{array}{c}3.0 \pm 1.6(4) \\
1.0(1)\end{array}$ & $\begin{array}{c}3.0 \pm 1.4(5) \\
1.0(1)\end{array}$ & $\begin{array}{c}3.7 \pm 2.1(5) \\
4.0(1)\end{array}$ \\
\hline
\end{tabular}

* Number of animals represented appears in parentheses; other values represent the means \pm SD.

$\dagger$ Density of GnRH immunoreactivity from digital photography of the ME and PVH; number of animals in parentheses

$\ddagger$ Density of GnRH immunoreactivity based on a five-point rating scale with 5 representing maximal amounts. 


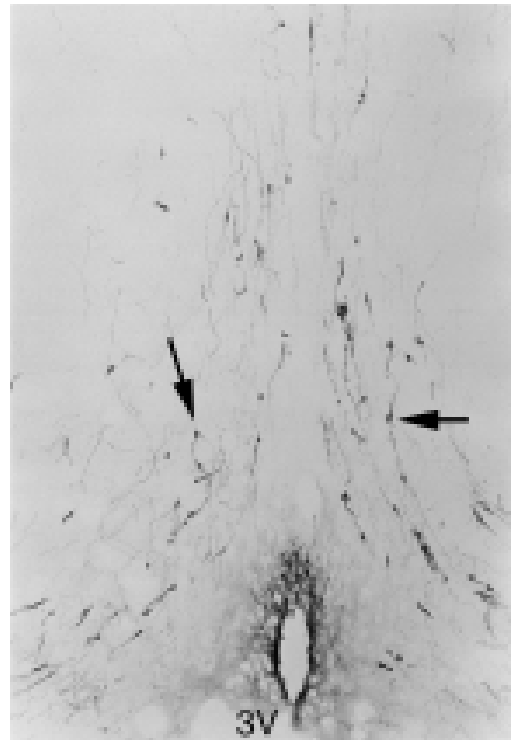

FIG. 4. Photomicrograph illustrating the region near the anterior third ventricle $(3 \mathrm{~V})$, which contains most of the GnRH neurons. The GnRH-IR cells can be seen dorsal and lateral to the OVLT, which is characterized by the convergence of GnRH-IR fibers. Original magnification $\times 125$.

treated animals, unpublished data) exhibited mean neurological scores of $8.9 \pm 0.5$, with no difference noted between age groups. Animals with moderate hydrocephalus at 21 days of age (18 rats) had a mean score of $8.1 \pm 1.1$, which was not significantly less than the score in age-matched counterparts. Animals with severe hydrocephalus at 21 and 50 days of age (10 rats) exhibited a mean score of $5.8 \pm 2.2$, which was significantly less $(\mathrm{p}<0.05)$ than both the age-matched controls and the moderate group of hydrocephalic animals.

\section{DISCUSSION}

In general, the immunohistochemical analyses of GnRH revealed surprisingly little effect of hydrocephalus in rats at 21 days of age. However, fiber density was decreased in the ME, and the proportion of spiny neurons was higher than normal at 50 days of age. It should be stressed that nearly all of the 21-day-old hydrocephalic animals exhibited severe or moderate ventriculomegaly, and their neurological function was impaired. Thus, the relative absence of morphological changes may mean that 3 weeks of progressive ventriculomegaly is not sufficient to alter the structure of GnRH cell bodies and projection fibers. A more protracted period of hydrocephalus seems to be required before reductions in fiber density and cell body types can be seen.

This lack of an early effect on periventricular fiber systems is not consistent with the multitude of findings from the periventricular white matter of the cortical mantle. The literature is replete with descriptions of axonal degeneration, demyelination, and reactive gliosis. ${ }^{13,32}$ These alterations are first seen within 6 hours of mild ventriculomegaly in the dorsolateral angle of the frontal horns, ${ }^{10}$ presumably due to mechanical forces that distort and stretch this specific region. Likewise, it is generally ac-

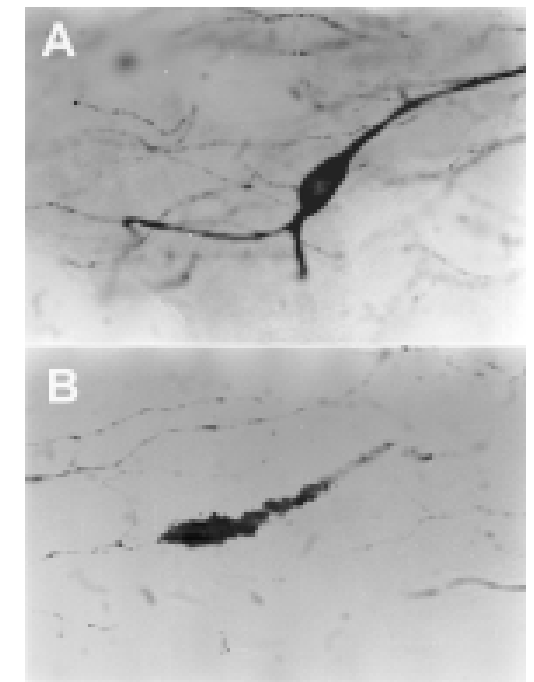

FIG. 5. Photomicrograph displaying representative smooth, more mature GnRH neurons in the OVLT (A) and spiny, less differentiated GnRH neurons (B) at 50 days of age. Original magnification $\times 125$

cepted that one of the reasons the periventricular white matter is vulnerable is because this tissue is stretched and compressed to a greater degree by the more expansive lateral ventricle. Authors of several recent studies have quantified changes in ventricular volume and demonstrated that the lateral ventricle does expand relatively more than the third ventricle. ${ }^{33}$ Therefore, one plausible explanation for the lack of periventricular damage to the hypothalamic GnRH system is that third ventricle expansion creates subthreshold mechanical forces requiring a considerable period of time to produce structural damage. If this theory is true, it also implies that concomitant cerebrospinal fluid pressure increases do not play a major role in the pathophysiology of the GnRH system.

Our findings are also different from those of Azzi, ${ }^{5}$ who observed an altered appearance and decreased density of vasopressin immunoreactive fibers 9 days after hydrocephalus was induced by kaolin injections in adult hamsters. Some of these fibers, which emanate from cell bodies in the supraoptic and paraventricular hypothalamic nuclei, course very near the floor of the third ventricle dorsal to the suprachiasmatic nuclei. In this position, they are just as close to the third ventricle as GnRH fibers, but they do not extend the same distance along the ventricular wall. Nevertheless, this periventricular axonal system exhibits more pronounced alterations than the GnRH system. This difference may be due to the older age at which hydrocephalus was induced in the hamsters, species differences, or perhaps that the GnRH system is somehow less vulnerable than the vasopressinergic system. More important, these temporal differences may be due to the acute onset of ventriculomegaly compared with the more protracted ventricular enlargement in the HTX rat, which tends to mimic the clinical presentation of precocious puberty in children. ${ }^{30}$

The hypothalamus of the newborn rat is poorly differentiated, 5 and some of the hypothalamic nuclei do not reach their maturation peak until the "critical period" (the first 
TABLE 3

Body weight of control and hydrocephalic HTX rats at death

\begin{tabular}{lcc}
\hline \hline Animal Group & No. of Animals & Mean Weight $(\mathrm{g})$ \\
\hline 21-day-old & & \\
control & 11 & $39.4 \pm 6.9$ \\
hydrocephalic & 12 & $42.9 \pm 1.0$ \\
50-day-old & & \\
control & 40 & $129.9 \pm 24.0$ \\
hydrocephalic & 1 & 128.0 \\
\hline
\end{tabular}

10 days after birth) for sexual differentiation. ${ }^{21}$ The differentiation and maturation of the hypothalamic GnRH system appears to fall in this category. Detectable levels of $\mathrm{GnRH}$ in rats have been reported as early as Day 12 of gestation. ${ }^{21}$ There is no significant change from Day 13 to 18 of gestation, but there is a significant rise in the level of the hypothalamic GnRH at Day 19 of gestation. After this initial rise, there is no significant change in the levels until Day 1 after birth, when a substantial (threefold) increase is noted., ${ }^{421}$ It is hypothesized that the early presence of hypothalamic GnRH serves as a differentiation factor for the pituitary gonadotrophs and, moreover, that the initial LH secretion in the fetus (gestation Day 18) is dependent on the presence of the hypothalamic GnRH., 2,42 There is a decline in the hypothalamic $\mathrm{GnRH}$ content from Day 5 to 17 after birth, followed by an increase from Day 17 to $25 .{ }^{43}$ A possible explanation for this decline may be an increase in the ability of the hypothalamus to release GnRH that results in the synthesis and release of LH from the pituitary. Once again, there is a rise in the hypothalamic GnRH content from Day 17 to $30 .^{4,43} \mathrm{Fi}$ nally, there is a significant reduction in the content of GnRH from Day 30 to 37, which coincides with vaginal opening and the LH surge in the female rat. ${ }^{29}$ After this period, the hypothalamic GnRH level follows a rhythmic pattern that is the basis of the observed hormonal changes responsible for the estrous cycle. Most forms of pediatric hydrocephalus, including the type represented by the HTX rat model, can perturb the developing hypothalamus during this period of GnRH system maturation.

Results in the present study demonstrate significantly higher levels (approximately eightfold) of $\mathrm{GnRH}$ in the hypothalamus of 21-day-old hydrocephalic rats compared with those in age-matched controls. The level of GnRH was also higher (approximately ninefold) in the hypothalamus of the 50-day-old hydrocephalic rat compared with that in age-matched controls. Due to an insufficient num-

\section{TABLE 4}

Relationship between severity of hydrocephalus and neurological examination score in HTX rats

\begin{tabular}{ccc}
\hline \hline $\begin{array}{c}\text { Hydrocephalus } \\
\text { Severity* }\end{array}$ & $\begin{array}{c}\text { No. of } \\
\text { Animals }\end{array}$ & $\begin{array}{c}\text { Neurolological } \\
\text { Examination Score } \dagger\end{array}$ \\
\hline normal & 87 & $8.9 \pm 0.5$ \\
moderate & 18 & $8.1 \pm 1.1$ \\
severe & 10 & $5.8 \pm 2.2 \ddagger$
\end{tabular}

\footnotetext{
* Based on lateral ventricle size and cortical mantle thickness.

$\uparrow$ Scored 0 to 3 on alertness, balance, and strength; see Table 1 for details.

$\doteqdot \mathrm{p}<0.05$.
}

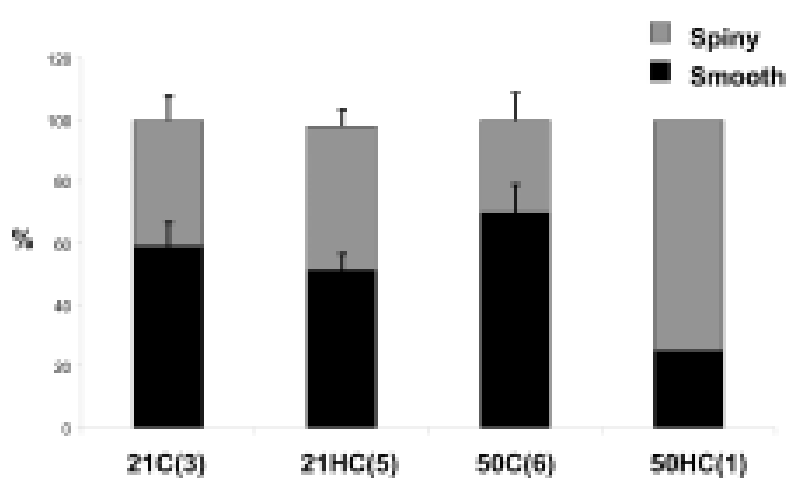

FIG. 6. Bar graph comparing the percentage of smooth and spiny cell types in the untreated hydrocephalic and control animals at 21 and 50 days of age. Note that with normal development in 21- and 50-day controls, there is a slight increase in the proportion of smooth neurons, which is expected with maturation. In contrast, the 50-day-old untreated hydrocephalic animal contains fewer smooth cell bodies, suggesting that development has been retarded.

ber of animals and the hormonal changes associated with the estrous cycle, the results in the 50-day-old group must be interpreted with caution.

There is a correlation between the level of some hormones (GnRH, LH, follicle-stimulating hormone, thyroidstimulating hormone, and prolactin) and the body weight in rats. ${ }^{26,28,29,31,34,37}$ Circulating $\mathrm{LH}$, thyroid-stimulating hormone, growth hormone, and prolactin levels are significantly depressed in acutely and chronically starved rats, ${ }^{31}$ and these conditions increase pituitary follicle-stimulating hormone but not $\mathrm{LH}^{29}$ The GnRH levels also increase during starvation and weight loss. ${ }^{28,29}$ To rule out the effects of body fat on GnRH measurements, we weighed the animals in all groups at the time of killing. Our results indicated no significant difference in the weight of hydrocephalic animals compared with the age-matched controls at the time of killing. These findings eliminate starvation and weight loss as a possible explanation for the elevation of $\mathrm{GnRH}$ in the hydrocephalic animals.

The significant GnRH increase in the 21-day-old group is most likely due to overproduction by the hypothalamus. Because our immunohistochemical studies did not indicate a significant change in fiber density, the GnRH is most likely transported to the nerve terminals and released rapidly. The notion of the overproduction of $\mathrm{GnRH}$ in the hydrocephalic pups is further supported by the increase in the proportion of spiny to smooth cells in these animals. As discussed previously, the spiny GnRH-containing cells represent a more immature cell type. ${ }^{51,52}$ These spiny neurons are also associated with the initial phase of hypothalamic injury that is followed by an increase in transforming growth factor $-\alpha$ and enhanced GnRH release. ${ }^{17}$ Furthermore, the spiny cells are thought to be responsible for the significant fluctuations in GnRH levels associated with the estrous cycle, whereas the smooth cells are involved in the simple, tonic secretion of GnRH. ${ }^{25}$ Moreover, results of other experiments in our laboratory have indicated an increase in the level of serum LH in the hydrocephalic pups as compared with age-matched controls. 
The release of LH from the pituitary is under the direct control of $\mathrm{GnRH}$, and the amount of $\mathrm{LH}$ released is proportional to the level of GnRH released from the hypothalamus. These findings support the hypothesis that hydrocephalus is associated with the overproduction of GnRH rather than the accumulation and/or impairment of release mechanisms in the hypothalamus.

In the case of the 50-day-old animals, the estrous cycle must be considered as an additional variable. Hypothalamic GnRH levels exhibit a cyclic pattern that dictates the changes in the estrous cycle, and not all of our measurements were taken on the same day of estrus. Moreover, we cannot draw strict conclusions given the small number of experimental animals, especially in the hydrocephalic group (that is, one rat). Nevertheless, our results indicated an increase in the level of GnRH in the 50-day-old animal compared with age-matched controls. Normally, the level of the hypothalamic GnRH gradually increases from diestrus to proestrus, and these levels reach their maximum in the morning of proestrus. This peak of GnRH is responsible for the LH surge in proestrus. We recorded the lowest level of GnRH in two control animals in metestrus. As expected, the GnRH levels in the two control animals in diestrus showed a slight elevation compared with the levels in metestrus. This pattern of increase in the GnRH level is supported by other data on the estrous cycle in different rat strains ${ }^{3,22,43}$ The hydrocephalic rat in the 50-dayold group was killed in proestrus, and the level of GnRH in this animal was approximately 9 times that in the control rats in diestrus. The rise in GnRH during proestrus in this animal may be normal; however, three strong points refute this possibility. First, the animal was killed at 4:00 p.m. on the day of proestrus. According to other studies of the rat estrous cycle, the GnRH peak is achieved in the morning of proestrus. ${ }^{3,22,43}$ Second, this animal did not have a regular estrous cycle and was arrested in proestrus, indicating the lack of a GnRH cyclic pattern. Third, the level of GnRH was significantly higher than those in successfully treated hydrocephalic animals that exhibit normal estrous cycles. Therefore, we believe that the high level of GnRH in this animal is due to damage of the hypothalamic GnRH system caused by longstanding hydrocephalus. This assertion is further substantiated by the high percentage of spiny GnRH cells in this animal as compared with that in controls.

\section{CONCLUSIONS}

This study appears to represent the first experimental analysis of the effects of perinatal and infantile hydrocephalus on the hypothalamic GnRH system. The results suggest that cellular mechanisms are mainly involved, rather than neuronal or axonal injury; thus the potential for reversing GnRH alterations is promising. Note, however, that our data do not answer questions relating to the clinical findings of precocious puberty occurring preferentially in girls who have been shunt-dependent since childhood but who usually present with small ventricles in premature adolescence. Likewise, we cannot shed new light on why adolescents and young adults with large ventricles and chronic hydrocephalus present with delayed puberty and amenorrhea. Ongoing studies involving shunt treatment in HTX rats will address these issues.

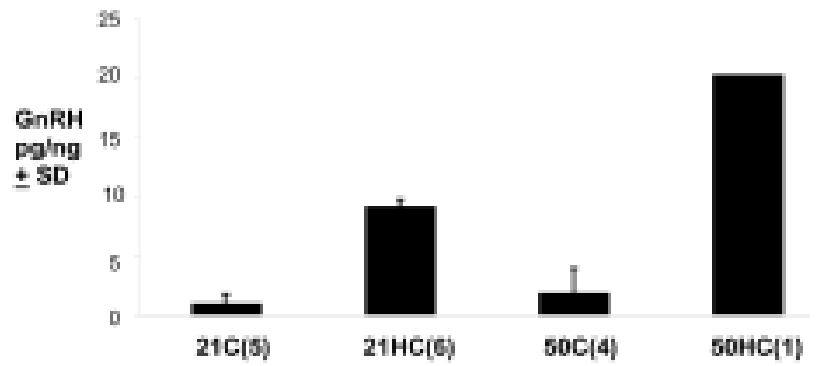

FIG. 7. Bar graph illustrating the amount of GnRH in the hypothalamus as measured by RIA. Values represent the group means \pm SDs. Numbers in parentheses indicate the number of animals in each group. Note the $8.4 \%$ increase in hydrocephalic animals at 21 days and the $10.3 \%$ increase at 50 days, relative to agematched controls.

\section{Acknowledgments}

We thank Blaine C. White, M.D., for scientific and personal guidance; Gloria Hoffman, Ph.D., and the members of her laboratory for technical advice with GnRH immunohistochemistry; and Alexa I. Canady, M.D., and Steven D. Ham, D.O., for clinical advice and encouragement. We are also grateful to Ronald Thomas, Ph.D., for statistical assistance; Yan Ning for help with immunohistochemistry; Clifford Pohl, Ph.D., for RIA analysis; and Nancy Triggs and Alfreda Johnson for secretarial support.

\section{References}

1. Abdolvahabi RM, Mitchell JA, Diaz FG, McAllister JP II: A brief review of the effects of chronic hydrocephalus on the gonadotropin releasing hormone system: implications for amenorrhea and precocious puberty. Neurol Res 22:123-126, 2000

2. Araki S, Toran-Allerand CD, Ferin M, Vane Wiele RL: Immunoreactive gonadotropin-releasing hormone $(\mathrm{Gn}-\mathrm{RH})$ during maturation in the rat: ontogeny of regional hypothalamic differences. Endocrinology 97:693-697, 1975

3. Asai T, Wakabayashi K: Changes of hypothalamic LH-RF content during the rat estrous cycle. Endocrinol Jpn 22:319-326, 1975

4. Aubert ML, Begeot M, Winiger BP, Morel G, Sizonenko PC, Dubois PM: Ontogeny of hypothalamic luteinizing hormonereleasing hormone (GnRH) and pituitary GnRH receptors in fetal and neonatal rats. Endocrinology 116:1565-1576, 1985

5. Azzi GM: Hydrocephalic-Induced Neuroanatomical and Pathophysiological Alterations in the Vasopressinergic System and Endocrine Hypothalamus of the Hamster. Detroit, MI: Wayne State University, 1994 (Dissertation)

6. Benito Lopez P, Lopez J, Lopez Zafra J, Jimenez Pereperez JA: [Gigantism and primary amenorrhea as manifestations of hydrocephaly.] Rev Clin Esp 180:375-377, 1987 (Sp)

7. Brauner R, Rappaport R, Nicod C, Malandry F, Thibaud E, Pierre-Kahn A, et al: [True precocious puberty in non-tumor hydrocephalus. An analysis of 16 cases.] Arch Fr Pediatr 44:433-436, 1987 (Fr)

8. Caporal R, Segrestaa JM, Dorf G: Endocrine expressions of hydrocephalus. A case of primary amenorrhoea revealing a stenosis of the foramen of Magendie. Acta Endocrinol (Copenh) 102: $161-166,1983$

9. Cholley F, Trivin C, Sainte-Rose C, Souberbielle JC, Cinalli G, Brauner R: Disorders of growth and puberty in children with non-tumoral hydrocephalus. J Pediatr Endocrinol Metab 14:319-327, 2001

10. Clark RG, Milhorat TH, Stanley WC, Di Chiro G: Experimental 
Pantopaque ventriculography. J Neurosurg 34:387-395, 1971

11. De Luca F, Muritano M, Rizzo G, Pandullo E, Cardia E: True precocious puberty: a long-term complication in children with shunted non-tumoral hydrocephalus. Helv Paediatr Acta 40: 467-472, 1985

12. Del Bigio MR, Bruni JE: Changes in periventricular vasculature of rabbit brain following induction of hydrocephalus and after shunting. J Neurosurg 69:115-120, 1988

13. Del Bigio MR, McAllister JP II: Pathophysiology of hydrocephalus, in Choux M, DiRocco CE, Hockley AD, Walker ML (eds): Pediatric Neurosurgery. Philadelphia: WB Saunders Co, 1999, pp 217-236

14. Elias ER, Sadeghi-Nejad A: Precocious puberty in girls with myelodysplasia. Pediatrics 93:521-522, 1994

15. Flaschka G, Argyropoulos G, Lanner G: [Primary amenorrhea, a symptom of occlusive hydrocephalus.] Wiener Medizinische Wochenschrift 129:633-635, 1979 (Ger)

16. Gautron JP, Pattou E, Bauer K, Kordon C: Hydroxyproline ${ }^{9} l u-$ teinizing hormone-releasing hormone: a novel peptide in mammalian and frog hypothalamus. Neurochem Int 18: 221-235, 1991

17. Goomer N, Saxena RN, Sheth AR: Correlation of hypothalamic LHRH, pituitary LH and plasma LH in developing rats. Endokrinologie 70:131-141, 1977

18. Gulati P, Jena AN, Marwaha R, Tripathi RP: Hydrocephalus presenting as precocious puberty. Indian Pediatr 30:107-108, 1993

19. Harris NG, Jones HC, Williams SC: MR imaging for measurements of ventricles and cerebral cortex in postnatal rats (H-Tx strain) with progressive inherited hydrocephalus. Exp Neurol 118:1-6, 1992

20. Hoffman GE, Lee WS, Attardi B, Yann V, Fitzsimmons MD: Luteinizing hormone-releasing hormone neurons express c-fos antigen after steroid activation. Endocrinology 126: 1736-1741, 1990

21. Hoffman GE, Smith MS, Fitzsimmons MD: Detecting steroidal effects on immediate early gene expression in the hypothalamus. Neuroprotocals 1:52-66, 1992

22. Jennes L, Stumpf WE, Sheedy ME: Ultrastructural characterization of gonadotropin-releasing hormone $(\mathrm{GnRH})$-producing neurons. J Comp Neurol 232:534-547, 1985

23. Jones HC, Bucknall RM: Inherited prenatal hydrocephalus in the H-Tx rat: a morphological study. Neuropathol Appl Neurobiol 14:263-274, 1988

24. Jones HC, Bucknall RM, Harris NG: The cerebral cortex in congenital hydrocephalus in the H-Tx rat: a quantitative light microscopy study. Acta Neuropathol (Wien) 82:217-224, 1991

25. Junier MP, Wolff A, Hoffman GE, Ma YJ, Ojeda SR: Effect of hypothalamic lesions that induce precocious puberty on the morphological and functional maturation of the luteinizing hormone-releasing hormone neuronal system. Endocrinology 131:787-798, 1992

26. Kalra PS, Kalra SP: Temporal changes in the hypothalamic and serum luteinizing hormone-releasing hormone (LH-RH) levels and the circulating ovarian steroids during the rat oestrous cycle. Acta Endocrinol (Copenh) 85:449-455, 1977

27. Kim CS, Bennett DR, Roberts TS: Primary amenorrhea secondary to noncommunicating hydrocephalus. Case report. Neurology 19:533-535, 1969

28. Knuth UA, Friesen HG: Starvation induced anoestrus: effect of chronic food restriction on body weight, its influence on oestrous cycle and gonadotrophin secretion in rats. Acta Endocrinol (Copenh) 104:402-409, 1983

29. Kotsuji F, Hosokawa K, Tominaga T: Effects of the daily administration of gonadotrophin-releasing hormone on the anterior pituitary gland of rats with restricted feeding. J Endocrinol 134:177-182, 1992

30. Lopponen T, Saukkonen AL, Serlo W, Tapanainen P, Ru- okonen A, Knip M: Accelerated pubertal development in patients with shunted hydrocephalus. Arch Dis Child 74: 490-496, 1996

31. Matsubara $M$, Nakagawa $K$, Akikawa K: Immunoreactive LHRH in chronic starved rats. Horm Metab Res 18:450-453, 1986

32. McAllister JP II, Chovan P: Neonatal hydrocephalus. Mechanisms and consequences. Neurosurg Clin N Am 9:73-93, 1998

33. McAllister JP II, Chovan P, Steiner CP, Johnson MJ, Luciano MG, Ayzman I, et al: Differential ventricular expansion in hydrocephalus. Eur J Pediatr Surg 8 (1 Suppl):39-42, 1998

34. McShane TM, Wise PM: Life-long moderate caloric restriction prolongs reproductive life span in rats without interrupting estrous cyclicity: effects on the gonadotropin-releasing hormone/luteinizing hormone axis. Biol Reprod 54:70-75, 1996

35. Meyer S, Landau H: Precocious puberty in myelomeningocele patients. J Pediatr Orthop 4:28-31, 1984

36. Moeslein S, Dericks-Tan JS, Lorenz R, Taubert HD: Doublestimulation with LH-RH in primary amenorrhea caused by chronic internal hydrocephylus: a case study. Gynecol Endocrinol 1:201-207, 1987

37. Nakanishi Y, Mori J, Nagasawa H: Recovery of pituitary secretion of gonadotrophins and prolactin during re-feeding after chronic restricted feeding in female rats. J Endocrinol 69: 329-339, 1976

38. Nett TM, Akbar AM, Niswender GD, Hedlund MT, White WF: A radioimmunoassay for gonadotropin-releasing hormone (GnRH) in serum. J Clin Endocrinol Metab 36:880-885, 1973

39. Paxinos G, Watson C: The Rat Brain in Stereotaxic Coordinates, ed 2. San Diego, CA: Academic Press, 1986

40. Peillon F, Boyet F, Fohanno D, Metzger J, Dreyfus G: [Amenorrhea of hypothalamic origin revealing hydrocephalus caused by latent stenosis of the aqueduct of Sylvius.] Ann Med Interne (Paris) 126:601-607, 1975 (Fr)

41. Picco P, Leveratto L, Cama A, Vigliarolo MA, Levato GL, Gattorno M, et al: Immotile cilia syndrome associated with hydrocephalus and precocious puberty: a case report. Eur J Pediatr Surg 3 (1 Suppl):20-21, 1993

42. Salisbury RL, Dudley SD, Weisz J: Effect of gonadotrophin-releasing hormone on circulating levels of immunoreactive luteinizing hormone in fetal rats. Neuroendocrinology 35: 265-269, 1982

43. Slob AK, Ooms MP, Vreeburg JT: Prenatal and early postnatal sex differences in plasma and gonadal testosterone and plasma luteinizing hormone in female and male rats. J Endocrinol 87: 81-87, 1980

44. Thibaud D, Thibaud E, Landrieu P, Zerah M: [Primary amenorrhea revealing congenital hydrocephalus.] Arch Pediatr 3: 1099-1101, 1996 (Fr)

45. Tomono Y, Maki Y, Ito M, Nakada Y: Precocious puberty due to postmeningitic hydrocephalus. Brain Dev 5:414-417, 1983

46. Trivin C, Couto-Silva AC, Sainte-Rose C, Chemaitilly W, Kalifa C, Doz F, et al: Presentation and evolution of organic central precocious puberty according to the type of CNS lesion. Clin Endocrinol (Oxf) 65:239-245, 2006

47. Trollmann R, Strehl E, Dorr HG: Precocious puberty in children with myelomeningocele: treatment with gonadotropin-releasing hormone analogues. Dev Med Child Neurol 40:38-43, 1998

48. Trollmann R, Strehl E, Wenzel D, Dorr HG: Does growth hormone $(\mathrm{GH})$ enhance growth in GH-deficient children with myelomeningocele? J Clin Endocrinol Metab 85:2740-2743, 2000

49. Turpin G, Heshmati HM, Darbois R, de Gennes JL: [A rare cause of amenorrhea: stenosis of the aqueduct of Sylvius. Apropos of 3 cases. Cure by ventriculo-atrial shunt.] Sem Hop 59:2369-2372, 1983 (Fr)

50. Wada M: Congenital hydrocephalus in HTX-rats: incidence, 
pathophysiology, and developmental impairment. Neurol Med Chir (Tokyo) 28:955-964, 1988

51. Wray S, Hoffman G: A developmental study of the quantitative distribution of LHRH neurons within the central nervous system of postnatal male and female rats. J Comp Neurol 252: 522-531, 1986

52. Wray S, Hoffman G: Postnatal morphological changes in rat LHRH neurons correlated with sexual maturation. Neuroendocrinology 43:93-97, 1986

Manuscript submitted February 26, 2007.
Accepted March 19, 2007.

This work was supported by the Department of Neurological Surgery at the Wayne State University School of Medicine as well as the Leede Hydrocephalus Research Fund and the Hydrocephalus Research Fund from the Children's Hospital of Michigan (J.P.M.II).

Address reprint requests to: James P. McAllister II, Ph.D., Department of Neurological Surgery, Wayne State University School of Medicine, University Health Center, Suite 6E, 4201 St. Antoine, Detroit, Michigan 48201. email: pmcallister@med. wayne.edu. 